\title{
DESAFIOS E POSSIBILIDADES NO \\ ESTÁGIO SUPERVISIONADO OBRIGATÓRIO: \\ A VISÃO DOS ESTUDANTES DO \\ CURSO DE ADMINISTRAÇÃO
}

\author{
SUPERVISED PROFESSIONAL TRAINING: \\ CHALLENGES AND OPPORTUNITIES FROM \\ THE POINT OF VIEW OF \\ BUSINESS ADMINISTRATION STUDENTS
}

Recebido em: 26/06/2012 Aprovado em: 07/08/2012 Avaliado pelo sistema double blind review

Editora Científica: Manolita Correia Lima

\section{MARIANE LEMOS LOURENÇO psimari@uol.com.br IOMARA SCANDELARI LEMOS JOSÉ EDUARDO PÉCORA JUNIOR UNIVERSIDADE FEDERAL DO PARANÁ}

RESUMO

Para acrescentar subsídios às discussões relacionadas ao estágio supervisionado obrigatório, este artigo tem o objetivo geral de analisar o processo de desenvolvimento de tais estágios, no Curso de Administração de uma Instituição de Ensino Superior (IES), na visão dos estudantes que já o completaram. Para atender a este propósito, foi realizada uma pesquisa que, em relação aos seus objetivos, mostrou-se como descritiva-explicativa, pois envolveu o uso de técnicas padronizadas de coleta de dados - neste caso, o uso do questionário, que foi endereçado via e-mail aos estudantes estagiários desta IES. A análise dos dados aconteceu por meio do tratamento estatístico das informações coletadas e da análise de conteúdo das respostas obtidas. Os resultados mostraram como principais dificuldades na IEs: a burocracia e o processo de orientação. Quanto às dificuldades encontradas nas organizações concedentes, ressaltam: a falta de supervisão na empresa e dificuldades em conciliar os estudos com o estágio. As possibilidades encontradas no decorrer do estágio compreendem: obter conhecimento global acerca da organização; estímulo à criatividade, à inovação e às habilidades de comunicação.

Palavras-chave: estágio supervisionado; organizações; ensino superior.

\footnotetext{
ABSTRACT

In order to add support for discussions related to supervised professional training, this article has the general objective of analyzing its developmental process in the Business Administration Course at a Higher Education Institution (HEI), from the point of view of students who have already completed their supervised professional training. Thus, research was conducted that should be considered descriptive-explicative in terms of its objectives, as it involved using pattern techniques of data collection - in this case, a questionnaire sent by e-mail to the students of the Higher Education Institution in question. Data analysis was carried out using both the statistical treatment of the information gathered, and content analysis. The results showed that bureaucracy and tutoring were the main challenges at the HEI, whilst a lack of supervision and difficulties in reconciling work and study were the other main challenges. The opportunities found comprised: obtaining global knowledge regarding the organization; and the incentive for developing creativity, innovation, and communication skills. Keywords: supervised professional training; organizations; higher education.
} 


\section{INTRODUÇÃO}

O Estágio Supervisionado Obrigatório consta em diversos projetos pedagógicos nos cursos de graduação em Administração no Brasil. Contudo, nas Diretrizes Curriculares do Curso de Administração, aprovadas em 2005, o estágio passou a ser um componente opcional para o currículo do curso, depois de I8 anos de obrigatoriedade (BRASIL, 2005).

Não obstante, permanecem as orientações que o avaliam como complemento para a formação acadêmica. "Esta mudança suscita a rediscussão de algumas questões que determinam o alcance e o impacto da realização do estágio na formação do profissional em Administração" (FESTINALLI; CANOPF; BERTUOL, 2007, p. I). De um lado, alguns autores destacam a importância dessa fase de estudos para a formação profissional (PICONEZ, I99I; PIMENTA, I995; ZABALZA, 2004), e enfatizam o estágio como instrumento imprescindível para o desenvolvimento de habilidades e competências essenciais ao administrador (ALMEIDA; LAGEMAN; SOUZA, 2006), e afirmam que os estágios são cada vez mais utilizados como ferramentas de aprendizagem para os alunos, sobretudo no preenchimento da lacuna entre o aprendizado em sala de aula e a prática de negócios (D’ABATE; YOUNDT; wenzel, 2009). Por outro lado, diversas Instituições de Ensino Superior (IES) começam a questionar o Estágio Supervisionado em seus Projetos Pedagógicos, alterando-lhe a configuração.

Para discutir esta problemática, este trabalho tem o objetivo geral de analisar o processo de desenvolvimento dos estágios obrigatórios do Curso de Administração de uma Instituição de Ensino Superior, na visão dos estudantes do Curso de Administração desta IEs, e que já realizaram o estágio supervisionado obrigatório, com os seguintes objetivos específicos: (I) identificar o perfil do estudante e os setores da economia nacional que mais oferecem estágios para a amostra pesquisada, assim como as condições de estágio nas empresas concedentes; (2) revelar a visão dos estudantes sobre o processo de estágio supervisionado obrigatório; (3) mostrar as dificuldades e as possibilidades encontradas pelos estudantes no decorrer do estágio; (4) relacionar as principais dificuldades na IEs e nas organizações concedentes 
de estágio. Esta pesquisa visa a contribuir, ainda, com questionamentos sobre a permanência ou não do estágio supervisionado obrigatório, em sua forma mais tradicional, com reflexões acerca da possibilidade de equiparar, no projeto pedagógico do Curso, o estágio, as atividades de extensão, de monitorias e de iniciação científica na educação superior, como dispõe a Lei $\mathrm{n}^{\mathrm{o}}$ II.788 de 25 de setembro de 2008 (BRASIL, 2008). 


\section{REFERENCIAL TEÓRICO}

\section{A LEGISLAÇÃO SOBRE ESTÁGIO SUPERVISIONADO}

O estágio curricular supervisionado foi instituído pela Lei Federal $\mathrm{n}^{\circ}$ 6.494, sancionada em 07 de dezembro de 1977 (BRASIL, I977), e regulamentado pelo Decreto Federal n. ${ }^{\circ} 87.497$ de I8 de agosto de 1982 (BRASIL, 1982). Nestes documentos o estágio supervisionado é definido como uma forma de complementar o ensino e a aprendizagem, proporcionando uma experiência prática na linha de formação do estudante. Já a atual legislação de estágio, a Lei $\mathrm{n}^{\circ}$ II.788 de 25 de setembro de 2008 (BRASIL, 2008), em seu artigo I ${ }^{\circ}$, define o Estágio como:

Ato educativo escolar supervisionado, desenvolvido no ambiente de trabalho, que visa à preparação para o trabalho produtivo de educandos que estejam frequentando o ensino regular em instituições de educação superior, de educação profissional, de ensino médio, da educação especial e dos anos finais do ensino fundamental, na modalidade profissional da educação de jovens e adultos (BRASIL, 2008).

A referida lei define no $\operatorname{artigo~} \mathrm{I}^{\circ}$ no parágrafo $\mathrm{I}^{\circ}$ que o estágio deve fazer parte do projeto pedagógico do curso, e no parágrafo $2^{\circ}$ esclarece que "o estágio visa ao aprendizado de competências próprias da atividade profissional e à contextualização curricular, objetivando o desenvolvimento do educando para a vida cidadã e para o trabalho" (BRASIL, 2008).

$\mathrm{O}$ artigo $2^{\circ}$ da Lei $\mathrm{n}^{\circ}$ II.788 esclarece, ainda, que "o estágio poderá ser obrigatório ou não obrigatório, conforme determinação das diretrizes curriculares da etapa, modalidade e área de ensino e do projeto pedagógico do curso". E no parágrafo $3^{\circ}$, no artigo $2^{\circ}$, estabelece que as atividades de extensão, de monitorias e de iniciação científica na educação superior, realizadas pelo estudante, poderão ser equiparadas ao estágio, quando previsto no projeto pedagógico do curso (BRASIL, 2008).

As Diretrizes Curriculares aprovadas para o Curso de Administração pela Resolução 4/2005 do Conselho Nacional de Educação (BRASIL, 2005), em seu Artigo $7^{\circ}$, dispõe sobre o Estágio Curricular Supervisionado como 
"um componente curricular direcionado à consolidação dos desempenhos profissionais desejados inerentes ao perfil do formando”, e seguindo a orientação de documentos anteriores (Lei 6.494/77; Decreto 87.497/82; Parecer I46/o2) enfatiza que cada Instituição de Ensino Superior deve organizar o programa de estágio curricular supervisionado, considerando o direcionamento dado ao projeto pedagógico do curso, sendo responsável pelo acompanhamento, supervisão, e avaliação do estágio curricular obrigatório.

O aspecto novo deste documento, em relação aos anteriores, é o fato de o estágio curricular obrigatório ser apresentado como atividade optativa para o currículo do Curso de Administração, conforme consta no Art. $7^{\circ}, \oint 3^{\circ}$ : "Optando a instituição por incluir no currículo do Curso de Graduação em Administração o Estágio Supervisionado de que trata este artigo...”.

Se esta for a opção, a IES "deverá emitir regulamentação própria, aprovada pelo seu Conselho Superior Acadêmico, contendo, obrigatoriamente, critérios, procedimentos e mecanismos de avaliação”... (Art.7 $7^{\circ}, \S 3^{\circ}$ ). Neste caso, o $\S \mathrm{I}^{\mathrm{o}}$ estabelece que: "O estágio de que trata este artigo poderá ser realizado na própria instituição de ensino, mediante laboratórios que congreguem as diversas ordens práticas correspondentes aos diferentes pensamentos das Ciências da Administração”. Podem ser incluídas nas atividades realizadas na própria instituição de ensino, as atividades de iniciação científica, monitorias e atividades de extensão, conforme dispõe em seu parágrafo $3^{\circ}$ a Lei $n^{\circ}$ II.788 de 25 de setembro de 2008 , entre outras práticas profissionais já pensadas em currículos de administração inovadores.

No entanto, o atual caráter opcional do estágio curricular obrigatório nas atuais diretrizes para os cursos de administração no Brasil gera muitas inquietações, como o exposto por Festinalli, Canopf e Bertuol (2007), que consideram a alternativa de não inclusão do estágio no currículo do curso como uma possibilidade "de enxugamento de estrutura nas IEs, que alocavam horas de pessoal para coordenação, orientação e trâmites burocráticos com organizações concessoras”. Na época do lançamento das Diretrizes de 2005, os presidentes do Conselho Federal de Administração (CFA) e da Associação Nacional da Graduação em Administração (ANGRAD), 
por meio de um comunicado nacional transmitido em setembro de 2005 (ANGRAD/CFA, 2005), demonstraram sua apreensão com a alternativa oferecida pela legislação. "O comunicado esclarece que o estágio continua a ser percebido, por essas instituições, como um componente fortalecedor do curso no qual se concretiza a relação entre a teoria e a prática para a consolidação do processo de ensino-aprendizagem" (FESTINALLI; CANOPF; BERTUOL, 2007).

Em face destas inquietações, faz-se relevante desenvolver um debate sobre este tema. Neste sentido, este trabalho aborda o processo de estágio na visão dos estudantes do Curso de Administração de uma IES, que revelaram sua experiência acerca do assunto, mostrando as dificuldades e possibilidades encontradas, e, de igual modo, questionaram a proposta de Estágio Curricular Obrigatório nos moldes mais tradicionais.

\section{OS DESAFIOS PARA ACADEMIA, ORGANIZAÇÕES E ESTAGIÁRIOS}

Objetivando atender às demandas de formação prática requeridas pelas organizações, o estágio obrigatório vem se tornando um importante meio de inserção profissional progressiva, porquanto estimula as universidades a ampliarem sua prática. (Oliveira; PICCININI; Retour, 20IO). Essa prática deve envolver o processo de ensino e aprendizagem e promover o desenvolvimento de técnicas e habilidades do futuro profissional funcionalidades que nortearão o posicionamento profissional do futuro administrador (Brasil, 2008 apud FRANCISCO et al., 20Io). É por intermédio do estágio que o estudante começa a familiarizar-se com as atividades do curso que está frequentando, além de representar um meio de inserção profissional (Ritnner, I999 apud OLIVEIRA; PICCININI; RETOUR, 20IO).

Sabe-se que a sala de aula garante o contato inicial com capacidades, conhecimento e bases científicas, mas apenas isso não é suficiente, porquanto administrar envolve ambas, ciência e técnicas aplicadas às organizações. Em havendo apenas a sala de aula, fica dificultada a educação gerencial, pois a prática é fundamental ao desenvolvimento de tal capacidade (MINTZBERG; GOSLING, 2003). 
A atividade de estágio - um elo entre o universo profissional e o espaço acadêmico - tem sido, segundo Nascimento e Teodósio (2005), alvo de várias das críticas desenvolvidas por professores orientadores de estágio, por supervisores de estagiários nas organizações e por estudantes - atores que vivenciam tal realidade.

Por estar na fronteira entre a formação e a atividade produtiva, o desconhecimento ou o mau entendimento sobre "o que é" e "como deve ser desenvolvido", o estágio leva à multiplicidade de práticas, que nem sempre priorizam a formação profissional do estudante. (OLIVEIRA; PICCININI; RETOUR, 20I0).

Assim, discussões que tratam das diferenças entre o mundo empresarial e o mundo universitário não são novas. Grynszpan (1999 apud FRANCISCO; SANTOS, 2005) reconhece estas diferenças, pois para o autor, "os dois setores, universitário e empresarial, têm dinâmicas e objetivos bem distintos e muitos desacordos existem e continuarão a existir. As contradições não ocorrem apenas no Brasil; é uma realidade comum a todos os países". De acordo com Nascimento e Teodósio (2005):

De um lado, é comum encontrar relatos vindos do mundo empresarial que apontam a dificuldade das universidades contemporâneas em acompanhar o ritmo frenético do desenvolvimento tecnológico e da produção de conhecimento. Por sua vez, na esfera acadêmica constrói-se uma percepção de que as atividades empresariais, sobretudo nos empreendimentos corporativos privados, são marcadas pela superficialidade e reprodução de modismos gerenciais (NASCIMENTO; TEODósIO, 2005).

Para Sancovschi, Fernandes e Siqueira (2009), as opiniões referentes ao estágio sempre variaram. Roesch (1996 apud SANCOvsCHI; FERNANDES; SIQUEIRA, 2009) afirma que o estágio é importante porque proporciona ao estudante, em especial àquele que nunca teve uma experiência de trabalho, a oportunidade de colocar em teste o que aprendeu, e oferece uma resposta objetiva às críticas dos profissionais atuantes de que há um hiato significativo entre o que se ensina na universidade e a realidade das empresas.

Na opinião de Chu, Kwan e Warning (2012), o estágio tem sido reconhecido como um importante método para preparar os estudantes 
para carreiras profissionais. Experiência prática, aprendizagens informais com profissionais ativos e exploração de aprendizado por meio de outras instituições (por exemplo, empresas e associações comunitárias) são formas fundamentais de refinar as habilidades dos alunos, ajudando-os a atingir novas percepções sobre suas profissões (Weinberg, 1986 apud CHU; KWAN; WARNING, 20I2), além do papel, que a prática profissional exerce ao possibilitar a aquisição de novas experiências (SANTOS; SILVA, 20I2).

Santos (2004 apud SANCOVSCHI; FERNANDES; SIQUEIRA, 2009), por sua vez, afirma que a preocupação com os estágios é excessiva, pois não existe teoria dissociada da prática ou prática sem teoria associada, mas sim um desconhecimento inconsciente de que a prática só ocorre com base numa fundamentação teórica, e que só há sentido na teoria se seu objeto estiver presente.

Todos parecem ter razão, mas, segundo Ferretti (I997 apud FRANCISCO; SANTOS, 2005), quando se fala em formação profissional, é mister enfocar as novas demandas que emergem na sociedade atual. Assim, é necessário rever e dimensionar as relações entre o sistema de formação profissional e o sistema educacional. Scorsolini-Comim, Matias e Inocente (2008) corroboram a ideia e afirmam que, ao se pensar na temática da formação profissional, há a necessidade de se abordar também o mercado de trabalho.

Assim, participam desta arena os diversos atores envolvidos: (I) professores orientadores de estágio queixando-se da precária formação dos graduandos ao se inserirem em estágios - muitos deles uma forma disfarçada de flexibilizar as restrições legais do mercado de trabalho, descaracterizandose como prática didático-pedagógica; (2) supervisores de estagiários nas organizações espantando-se com a desatualização e inutilidade de vários conteúdos estudados pelos graduandos; (3) estudantes desenvolvendo relações paradoxais com a atividade de estágio: a) oportunidade de aplicar conhecimentos construídos no espaço hermético e distante da realidade (marca dos cursos de graduação em Administração), ou b) caminho obrigatório para a sobrevivência no curso, na medida em que geram rendimentos, ou, ainda, c) aqueles que enxergam no estágio apenas mais 
uma exigência a ser cumprida em direção à tão sonhada formatura e ao desligamento do curso (NASCIMENTO; TEODósıo, 2005).

Na opinião de Sancovschi, Fernandes e Siqueira (2009), há importantes contradições associadas aos estágios realizados por estudantes de cursos de graduação. Uma das contradições reside no fato que todos - estudantes, professores, empregadores - concordam que os estágios complementam e enriquecem o conteúdo dos cursos, submetendo o que está sendo aprendido ao teste da realidade. Nenhum destes atores, porém, deseja que tal experiência comprometa as atividades acadêmicas, o que gera desafios a todos os atores envolvidos.

\section{DESAFIOS PARA OS PROFESSORES ORIENTADORES}

Mediante a relação entre o conhecimento e a atividade prática, que deve ser feita pelo estágio sob a orientação de um professor, o estudante é capaz de fazer a ligação entre o saber e o fazer (MESQUITA; FRANÇA, 2OII).

O orientador é "alguém que indica os caminhos, os rumos fazendo com que a pessoa se situe, reconheça o lugar onde se encontra para prosseguir a caminhada, para se guiar no caminho" (Petri, 2005, p. I48, apud TORREs; DALFOVO, 2OII).

Muritiba et al. (2008) postulam que um dos fatores que influenciam o maior ou o menor êxito dos estudantes dos cursos de graduação no mercado de trabalho é a preocupação constante de vários públicos, entre eles os professores, que procuram assegurar-se de que estão provendo o melhor para que seus estudantes sejam profissionais de sucesso no futuro. Assim, como local fundamental no desenvolvimento de experiências novas e significativas para o desenvolvimento pessoal e profissional, o ambiente da educação formal contribui para a reflexão das experiências já vivenciadas (sılva et al., 20I2). Na função de educar, o professor orientador é visto como profissional da prática, na medida em que o estágio passa a ser o "ensino na prática”, representando o prolongamento das tarefas confiadas ao estudante no estágio. Estas exigem grande esforço do estagiário. Daí a relevância do papel de ensinar do professor que irá orientar o estudante-estagiário, 
focalizando no seu treino profissional (BURIOLLA, 2008) e despertar nele o verdadeiro sentido da valorização profissional, pois, no cumprimento do estágio, ele terá de exercer funções condizentes com sua condição de universitário (ALBUQUERQUE; SILVA, 2006).

Assim, na opinião de Rodrigues e Carmo (2010), o professor orientador é o principal intermediário nesta relação entre unidade de ensino e unidade organizacional, pois ele tem a visão deste processo de aprendizagem - fato que, somado à criação de uma relação de cumplicidade entre supervisor e supervisionado garante sua execução na íntegra. "O saber orientar está associado a uma competência didática do professor orientador, que exige, inclusive, capacidade de relacionamento com o aluno orientando." (DIAS; PATRUS; MAgALHÃes, 20II, p. 70I).

Para que isto ocorra, "além de refletir, sistematizar e aplicar os conhecimentos adquiridos em sala de aula nas atividades práticas e reais do mercado de trabalho" (ALBUQUeRQUe; SILVA, 2006), Carvalho (2009) afirma que o professor orientador deveria desempenhar atribuições que envolvem a realização de visitas periódicas aos locais de estágio e ao recebimento de informações por parte dos supervisores responsáveis pelo estagiário na organização, que indicassem os pontos fortes e as deficiências do estudante. Ademais, o professor teria, ainda, que verificar se as tarefas desempenhadas se relacionam com os conteúdos profissionais e isto se desdobraria em outras atividades na instituição de ensino: encontros sistemáticos com os estudantes, análise dos principais problemas encontrados e das atividades desempenhadas pelos estudantes.

Cabe ao professor supervisor do estágio orientar o estudante no sentido de que ele alcance a maturidade necessária, sem que fique estressado ou ansioso, pelo fato de ter pouco tempo para a realização do estágio (albuQuerque; SILVA, 2006), e que privilegiem o desenvolvimento de habilidades, permitindo ao estudante identificar novas estratégias na busca de resolução de problemas - mesmo que tenham de acrescentar aos métodos tradicionais outros métodos para desenvolver o raciocínio e a capacidade crítica - que possam liberar a criatividade do estudante (Leite; Brandão, 1999 apUd MESQUITA; FRANÇA, 2OII). 
A grande lição que se busca deixar para o estudante é o fato de que não é possível aprender tudo de uma só vez e em tão pouco tempo. O mais importante será analisar cada tarefa que lhe for atribuída e procurar, com zelo, desempenhá-la da melhor forma possível, oferecendo sugestões que possam contribuir para o próprio desenvolvimento bem como para o do estágio (AlBUQUERQUE; SILVA, 2006).

\section{DESAFIOS PARA OS SUPERVISORES NAS ORGANIZAÇÕES}

Para as organizações, o estágio é um mecanismo, que possibilita formar um profissional de acordo com os interesses e os objetivos das mesmas; percebe-se o interesse da comunidade empresarial nos benefícios dos estágios para as organizações (MURARI; HELAL, 20IO; AQUINO; TOMASSINI, 2008). Elas passam a ter um período maior de avaliação para a contratação de futuros profissionais, sem custos trabalhistas, e também têm acesso a profissionais qualificados e com formação recente. Neste período de interação com o estudante, a empresa pode avaliar e treinar um potencial futuro funcionário de forma eficaz e econômica, o que as permite investir em novos talentos, adquirir conhecimento e renovar sua equipe (AQUINO; TOMASSINI, 2008).

No entanto, algumas empresas acreditam que a única vantagem em se contratar um estagiário é a possibilidade de conseguir mão de obra qualificada e de baixo custo, o que significa limitar e transgredir a base principal para a qual os estágios foram criados. Deste tipo de percepção, surge uma série de disfunções e utilizações equivocadas da noção de estágio. O melhor exemplo disso talvez seja a sua utilização como forma de acesso à mão de obra barata. Esta postura impede que o estagiário possa render todo o seu potencial e, ao término do contrato, pouco acrescenta à sua formação profissional ou a seu currículo (Domingo, 2002 apud OLIVEIRA; PICCININI; RETOUR, 2OIO; AQUINO; TOMASSINI, 2008).

Mas, o ambiente empresarial mudou significativamente, tornandose muito mais imprevisível, dinâmico e mutável (ARAÚjo et al., 20I2). Assim, a interface entre os estudantes de graduação e as empresas é de suma importância, pois além de representar oportunidades de trabalho, 
desenvolvem as habilidades desses estudantes, indo além da sala de aula e preparando-os para o mercado (MESQUITA; FRANÇA, 20II).

Entretanto, para Sancovschi, Fernandes e Siqueira (2009), existe uma situação complexa vivida pelos administradores de empresas, que contratam os estagiários. Eles normalmente têm a obrigação de atender às demandas de clientes, de funcionários, de fornecedores, de investidores, das instituições financeiras, e dos agentes fiscalizadores dos governos. Mas, quando oferecem oportunidades de estágio, expõem-se, também, às demandas dos estudantes em busca das primeiras vivências profissionais; dos professores que moldam as expectativas dos estudantes; e dos administradores das faculdades, que querem ver seus estudantes empregados em organizações de prestígio, realizando tarefas interessantes e compatíveis com a profissão que irão exercer.

\section{DESAFIOS PARA OS ESTUDANTES}

Diversos estudos indicam que, embora o estágio possa ser vantajoso para os estudantes - como forma de aprendizado e da profissão que desejam seguir, muitas empresas delegam a eles tarefas e responsabilidades antes atribuídas a funcionários efetivos. O estágio, que tinha como proposta ser um meio de aprendizado prático e a complementação de estudos, torna-se uma inserção precária, porquanto as exigências antes requeridas de funcionários são agora demandadas para um contrato que não assegura os benefícios legais (OLIVEIRA; PICCININI; RETOUR, 20IO).

Outro fator agravante relaciona-se à entrada no ensino universitário de públicos anteriormente excluídos de tal espaço. A figura do "estudante que trabalha" parece estar dando lugar ao "trabalhador que estuda". A opção do estudante de Administração pela experiência prática de trabalho, objeto de desejo de muitos graduandos, tem se tornado não mais opção, mas obrigação com vistas à sua manutenção no espaço acadêmico. (NASCIMENTO; TEODÓsIO, 2005).

Em alguns casos, o estágio assume a importância de um emprego, em detrimento do estudo: 
O aprendizado prático tem maior reconhecimento, e, a cobrança do estudante normalmente é a mesma de um trabalhador. As cobranças de horário e disponibilidade, bem como as suas responsabilidades podem assumir uma dimensão em que esta prática se torna mais importante do que o curso universitário, deixado em segundo plano. (OLIVEIRA; PICCININI; RETOUR, 20IO). Entretanto, para Murari e Helal (20I0), o estágio em Administração é um mecanismo que permite o desenvolvimento de competências profissionais, e contribui de maneira significativa para a inserção do estudante no mercado de trabalho. Dessa forma, a remuneração deveria, na opinião de Sancovschi, Fernandes e Siqueira (2009), representar simplesmente uma ajuda de custo; porém, alguns estudantes contam com esse auxílio para se manterem durante o curso. Assim, na expectativa de maiores ganhos, os estudantes se sentem incentivados a assumir responsabilidades incompatíveis com seus cursos e seus programas de estudo.

O estágio pode significar uma das atividades mais importantes na formação do jovem profissional; mas, para que tal possibilidade se concretize, é necessário haver compatibilidade entre os conteúdos desenvolvidos na formação escolar e as tarefas designadas para os estagiários nos locais de estágio. Cumpre às instituições de ensino definir e negociar as atividades a serem realizadas com os locais, que oferecem as oportunidades de estágio, além de supervisionar se os compromissos assumidos vêm sendo adequadamente atendidos. (CARVALHO, 2009).

Assim, o estágio deveria ocorrer em empresas que oferecem ao estudante a experiência prática (MURARI; HELAL, 20IO), e com mais ênfase nas Faculdades de Administração, em programas customizados ou ministrados dentro da empresa, conforme o entendimento de Fonseca et al. (2007), de forma a gerar atitudes, habilidades e competências tais como: relacionamento interpessoal, comunicação eficaz, liderança, solução de conflitos, adaptação a mudanças, articulação, visão do todo, criatividade e inovação, e multiculturalismo. Liu, Xu e Weitz (20II) defendem que as características definidoras de um programa de estágio implementado com sucesso incluem pelo menos três resultados, que indicam a utilidade do estágio, tanto para o estagiário 
quanto para a organização concedente: o estagiário deve achar as suas tarefas de trabalho interessantes e gostar de vir trabalhar todos os dias; deve considerar a organização um lugar atrativo para trabalhar; deve ter uma avaliação global positiva do trabalho da organização. "Destaca-se o estágio como uma ferramenta voltada para o desenvolvimento de habilidades e competências necessárias ao estudante" (MURARI; HELAL, 20IO, p. 03).

Para Festinalli, Canopf e Bertuol (2007), o estudante poderia adquirir as habilidades da prática profissional estando presente nas organizações de negócios para observar, compreender e adotar as práticas avaliadas como eficazes e utilizadas pelos administradores experientes, pois isto teria impacto tanto na questão salarial, conforme argumenta Link (1975 apud MURITIBA et al., 2008), quanto nos seus primeiros estudos, onde foram analisados, além da influência da qualidade da universidade e da experiência do estudante, as suas habilidades sobre seus ganhos após formado. Além disso, "entende-se o estágio como uma oportunidade para aperfeiçoamento das habilidades de relacionamento interpessoal." (FESTINALLI; CANOPF; BERTUOL, 2007, p. 9). Para Francisco et al. (2010, p. 213):

Graças à relação direta entre teoria e prática, desenvolvida nas atividades de Estágio Curricular Obrigatório, o candidato ao título de Bacharel em Administração terá a oportunidade de consolidar seus conhecimentos e gerar um alto valor agregado às empresas. Graças a isso, os valores e conhecimentos colimados ao longo do curso são importantes à aplicação dos conhecimentos e ao desenvolvimento de habilidades, que constroem atitudes eficazes à resolução de problemas enfrentados pelas organizações.

Com base nestes elementos conceituais, aqui apresentados, foi possível conduzir a pesquisa, segundo os procedimentos metodológicos detalhados a seguir. 


\section{METODOLOGIA}

A pesquisa realizada mostra-se, em relação aos seus objetivos, como descritiva-explicativa. Gil (1999) e Triviños (1987) definem pesquisas descritivas como aquelas com o objetivo de descrição das características de determinado fenômeno ou o desejo de conhecer as características de um grupo. Para tanto, este tipo de pesquisa envolve o uso de técnicas padronizadas de coleta de dados, como o uso do questionário. Para Gil (I999), pesquisas explicativas são aquelas que buscam identificar os fatores, que determinam ou que contribuem para a ocorrência dos fenômenos.

Do ponto de vista de abordagem do problema, a pesquisa é quantitativa e qualitativa, de acordo com Neves (I996, p. 2), uma vez que esses enfoques não se excluem, pois não se pode declarar que se opõem como instrumentos de análise, "na verdade, complementam-se e podem contribuir, em um mesmo estudo, para um melhor entendimento do fenômeno estudado". Laville e Dione (I999) lembram que o importante é que a abordagem escolhida esteja em prol do objeto de pesquisa.

Para a apresentação dos processos metodológicos realizados durante a análise dos dados, apresentam-se a seguir os dois pólos de abordagem, onde são apresentados os procedimentos cumpridos na pesquisa quantitativa bem como na qualitativa, além das exigências da análise de conteúdo, segundo Bardin (20II).

\section{ABORDAGEM QUANTITATIVA}

O método quantitativo caracteriza-se pelo emprego da quantificação tanto na coleta de dados, quanto no tratamento dos mesmos por meio de técnicas estatísticas (RICHARDSON, I999), sendo adequado para analisar o problema de forma objetiva. A natureza desta pesquisa é aplicada, pois gera conhecimentos para a execução prática e solução de problemas específicos, segundo a definição de Silva e Menezes (200I).

A coleta de dados foi realizada por meio de um questionário estruturado, elaborado com perguntas abertas e fechadas. O questionário foi endereçado via e-mail aos estudantes estagiários da instituição estudada. O pré-teste 
foi realizado com $3 \%$ de respondentes, no período de 9 a I4 de agosto de 20II. Após sofrer as modificações necessárias, a pesquisa foi aplicada de I6 a 23 de agosto de 20II. O questionário foi enviado para Iı2 estudantes, que correspondem aos alunos matriculados em estágio obrigatório no primeiro semestre de 20II, aprovados ou não, equivalendo a aproximadamente I3\% da população. Dos II2 estudantes que receberam o questionário, 79 responderam-no. Configura-se, assim, como uma amostragem intencional por adesão, de acordo com Martins e Théophilo (2009).

\section{ABORDAGEM QUALITATIVA}

$\mathrm{Na}$ abordagem qualitativa foi utilizada a análise de conteúdo que leva os pesquisadores a uma maior compreensão da natureza do fenômeno, independentemente das técnicas estatísticas usadas. A análise de conteúdo seria, segundo Bardin, "um conjunto de técnicas de análise das comunicações que utiliza procedimentos sistemáticos e objetivos de descrição do conteúdo das mensagens" (BARDIN, 20II, p. 44).

$\mathrm{Na}$ análise de conteúdo, Bardin (20II) distingue como basilares tanto a fase da descrição ou preparação do material, como a inferência ou dedução e a interpretação. Deste modo, os aspectos fundamentais da pré-análise seriam a leitura flutuante (leituras de contato com os textos), a escolha dos documentos (no caso os textos das questões abertas das entrevistas), a formulação das hipóteses e objetivos (relacionados ao estágio supervisionado obrigatório), a referenciação dos índices e elaboração dos indicadores (a frequência de aparecimento) e a preparação do material.

\section{OBJETIVOS}

Este estudo teve o objetivo geral de analisar o processo de desenvolvimento dos estágios obrigatórios do Curso de Administração de uma Instituição de Ensino Superior, na visão dos estudantes do Curso de Administração desta IES, e que já realizaram o estágio supervisionado obrigatório, com os seguintes objetivos específicos: (I) identificar o perfil do estudante e os setores da economia nacional que mais oferecem estágios para a amostra pesquisada; (2) revelar a visão dos estudantes sobre o processo de estágio 
supervisionado obrigatório; (3) mostrar as dificuldades e possibilidades encontradas pelos estudantes no decorrer do estágio; (4) relacionar as principais dificuldades na IEs e nas organizações concedentes de estágio.

\section{AMOSTRAGEM}

O estudo foi realizado com estudantes do Curso de Administração, de um município do estado do Paraná. Este público foi escolhido por se considerar relevante entender qual a visão dos estagiários, com base em sua experiência no processo de estágio obrigatório. A análise dos dados aconteceu por meio do tratamento estatístico das informações coletadas, permitindo a apreciação de frequência das respostas. O instrumento de coleta de dados possibilitou que, ao término de algumas questões, o entrevistado expressasse suas sugestões e considerações relativas àquela questão. Do ponto de vista qualitativo, estas respostas receberam análise de conteúdo de modo a agrupar elementos comuns e identificar elementos discriminantes (ambos relevantes ao estudo).

O nível da análise é organizacional, tendo em vista que está relacionado ao processo de estágio supervisionado em uma Instituição de Ensino Superior (IES). A unidade de análise, por sua vez, é individual, pois considerou os estudantes do Curso de Administração, que se matricularam na disciplina estágio supervisionado no $\mathrm{I}^{\mathrm{o}}$ semestre de 20II. A seguir, são apresentados os resultados do estudo. 


\section{RESULTADOS E DISCUSSÃO}

Nesta seção são apresentados os resultados e as discussões referentes à abordagem quantitativa e à abordagem qualitativa, respectivamente.

\section{ABORDAGEM QUANTITATIVA}

A abordagem quantitativa permitiu apresentar os resultados e a discussão acerca do perfil dos estudantes, das atividades econômicas e condições de estágio, nas empresas concedentes e os desafios para professores orientadores na IES, supervisores nas organizações e estagiários, conforme segue.

\section{PERFIL DOS ESTUDANTES}

Inicialmente, identificou-se o perfil dos 79 estudantes participantes do estudo. Observou-se que $24, \mathrm{I} \%$ possuem entre I6 e 20 anos; 59,5\% entre 2I e 25 anos; $15,2 \%$ entre 26 e 30 anos; e I,3\% possuem mais de $3 \mathrm{I}$ anos. Destes, $55,7 \%$ são do gênero feminino e $44,3 \%$ do gênero masculino. Entre os estudantes, $87,3 \%$ são solteiros e II,4\% são casados (Gráfico I). Com relação a filhos, $96,2 \%$ não possuem nenhum, e 3,8\% possuem um filho. 
Gráfico 1 Perfil dos Estagiários

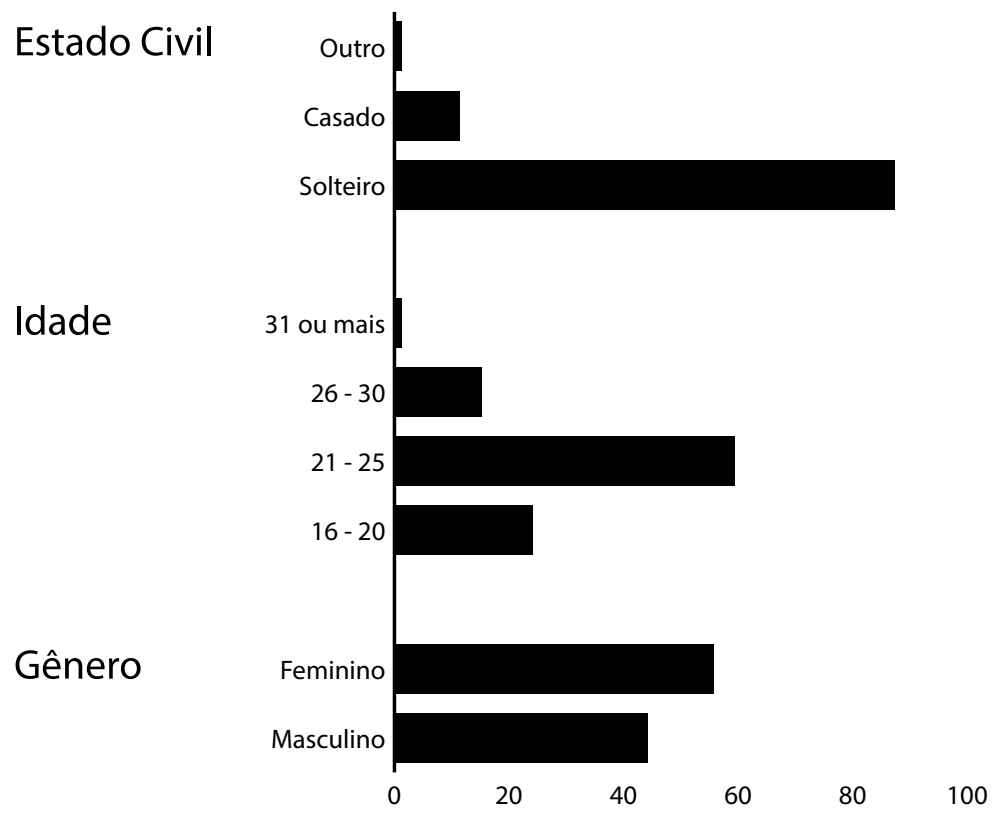

Em relação ao turno em que frequentam as aulas, $36,7 \%$ são do diurno e $63,3 \%$ do turno noturno. Com relação ao período do curso, $60 \%$ dos estudantes que se matricularam para a disciplina estágio supervisionado obrigatório estão nos três períodos finais do curso sendo: $28 \%$ de estudantes do $8^{\circ}$ período; $12 \%$ do sétimo período; $20 \%$ do sexto período; $7 \%$ do quinto período; e $4 \%$ de estudantes matriculados entre o $2^{\circ}$ e o $4^{\circ}$ período. Nesta IES, no Curso de Administração, é permitido aos estudantes cursarem a disciplina de estágio supervisionado somente a partir do $2^{\circ}$ período, em disciplinas do $\mathrm{I}^{\mathrm{o}}$ período, que transmitem conhecimentos gerais das diversas áreas da administração.

Para 77,2\% dos estudantes, Administração é o seu primeiro curso superior; $8,9 \%$ dos estudantes já possuem outro curso superior completo; $5,1 \%$ fazem simultaneamente outro curso de graduação e $8,9 \%$ possuem outro curso superior incompleto.

Todos os estudantes que participaram do estudo realizaram matrícula na 
disciplina de estágio supervisionado obrigatório. Destes, 88,6\% concluíram a disciplina, o que envolve o cumprimento de 300 horas de estágio, na empresa onde realizam suas atividades de estágio curricular obrigatório; além disso, obrigam-se ao comparecimento a reuniões de orientação com o professor orientador de estágio na universidade, à entrega de diversos trabalhos, conforme determina o Regulamento de Estágio Obrigatório do Curso, e as demandas de trabalhos de leituras sugeridas pelo professor orientador, em consonância com as deliberações do Regulamento de Estágio Obrigatório do Curso. Dos estudantes que participaram do estudo, II, $4 \%$ não concluíram a disciplina Estágio Supervisionado Obrigatório.

Com base nestas considerações, a próxima seção apresenta um panorama dos setores da economia que mais oferecem estágio na área de administração geral e aplicada (para a amostra estudada) e as condições de trabalho oferecidas pelas empresas onde os estudantes realizaram seus estágios.

\section{ATIVIDADES ECONÔMICAS E CONDIÇÕES DE ESTÁGIO NAS EMPRESAS CONCEDENTES}

Para fornecer um panorama dos setores da economia nacional que mais oferecem estágios para a amostra pesquisada (relacionada aos estagiários de uma IEs na área de Administração Geral e Aplicada), uma questão solicitava aos estagiários que indicassem a empresa onde realizavam seu estágio. Cada empresa foi alocada dentre as divisões das atividades da Economia Nacional por meio da base de dados da Classificação Nacional de Atividades Econômicas (CNAE, 2007) do Instituto Brasileiro de Geografia e Estatística (IBGE). Os setores com maior oferta de estágio para a amostra pesquisada, segundo a base de dados CNAE (2007), seriam: o de Indústrias de Transformação, com 29,I\% dos estagiários alocados neste setor, seguido pelo de Atividades Financeiras, de Seguros e Serviços Relacionados - com I7,8\%, e o setor de Administração Pública, Defesa e Seguridade Social - com I2,7\% de estagiários em empresas neste setor, conforme mostra a Tabela I. 
Tabela 1 Estagiários por setor de Atividades Econômicas

\begin{tabular}{|c|c|c|c|}
\hline \multicolumn{2}{|c|}{ Atividade Econômica } & \multirow{2}{*}{$\begin{array}{l}\text { Frequência } \\
\text { - }\end{array}$} & \multirow[t]{2}{*}{ Percentual (\%) } \\
\hline A. & Agricultura, pecuária, produção florestal, pesca e aquicultura & & \\
\hline B. & Indústrias Extrativas & - & \\
\hline C. & Indústrias de Transformação & 23 & 29,1 \\
\hline D. & Eletricidade e gás & - & \\
\hline E. & $\begin{array}{l}\text { Água, esgoto, atividades de gestão de resíduos e } \\
\text { descontaminação }\end{array}$ & - & \\
\hline F. & Construção & 1 & 1,3 \\
\hline G. & Comércio, reparação de veículos automotores e motocicletas & 7 & 8,9 \\
\hline $\mathrm{H}$. & Transporte, armazenagem e correio & 6 & 7,6 \\
\hline I. & Alojamento e alimentação & - & \\
\hline J. & Informação e Comunicação & 6 & 7,6 \\
\hline $\mathrm{K}$. & Atividades financeiras, de seguros e serviços relacionados & 14 & 17,8 \\
\hline L. & Atividades imobiliárias & - & \\
\hline M. & Atividades profissionais, científicas e técnicas & 5 & 6,3 \\
\hline N. & Atividades administrativas e serviços complementares & - & \\
\hline O. & Administração pública, defesa e seguridade social & 10 & 12,7 \\
\hline P. & Educação & 2 & 2,5 \\
\hline Q. & Saúde humana e Serviços Sociais & 2 & 2,5 \\
\hline R. & Artes, cultura, esporte e recreação & - & \\
\hline S. & Outras atividades de serviços & 3 & 3,79 \\
\hline $\mathrm{T}$. & Serviços domésticos & - & \\
\hline U. & $\begin{array}{l}\text { Organismos internacionais e outras instituições } \\
\text { extraterritoriais }\end{array}$ & - & \\
\hline Total & 79 & 100 & \\
\hline
\end{tabular}

Fonte: Elaborada pelos autores com base nos dados da pesquisa, de acordo com a CNAE (2007).

Outra questão solicitava aos estudantes matriculados na disciplina de estágio obrigatório, participantes do estudo, que indicassem as áreas funcionais das atividades executadas durante o estágio supervisionado obrigatório, na área de Administração Geral e Aplicada. As áreas de atuação foram definidas pela Comissão Orientadora de Estágio do Curso de Administração da IEs, de acordo com o mencionado no projeto pedagógico do curso e na grade curricular. A área predominante foi a de Organizações, com 27,8\% dos 
estagiários realizando suas atividades; seguida de Finanças com 20,3\%; Logística com I9\%; Gestão de Pessoas com 16,5\% e Marketing com ıo,1\% dos estagiários nesta área. Os estagiários indicaram que as melhores bolsas de estágio concentram-se na área de Finanças; seguida por Organizações; Gestão de Pessoas e Marketing. A Tabela 2 mostra a faixa salarial da bolsa recebida pelos estagiários, cujos valores concentram-se em maior porcentagem entre $\mathrm{R} \$$ I.00I,00 a R\$ I.500,0 (25,3\%) e entre R\$ 75I,00 a R\$ I.000,00 (24,I\%).

Tabela 2 Faixa salarial da bolsa estágio

\begin{tabular}{|lll|}
\hline Faixa Salarial (R\$) & Frequência & Percentual (\%) \\
\hline 2.000 ou mais & 8 & 10,1 \\
\hline de 1501 a 2000 & 13 & 16,5 \\
\hline de 1001 a 1500 & 20 & 25,3 \\
\hline de 751 a 1000 & 19 & 24,1 \\
\hline de 501 a 750 & 15 & 19 \\
\hline ate 500 & 3 & 3,8 \\
\hline Não remunerado & 1 & 1,3 \\
\hline Total & $\mathbf{7 9}$ & $\mathbf{1 0 0}$ \\
\hline
\end{tabular}

Além da bolsa estágio, alguns estudantes participantes do estudo mencionaram receber benefícios nas organizações onde atuam, tais como: auxílio transporte e alimentação; e, em menor frequência, benefícios de saúde e odontológico. O maior número de benefícios é oferecido aos estagiários que atuam na área de Logística, seguida de Finanças e Gestão de Pessoas.

Outro aspecto também mencionado pelos estagiários é a flexibilidade de horários: $17,4 \%$ podem escolher e remanejar seu próprio horário de trabalho; em contrapartida, II, $4 \%$ não possuem nenhuma flexibilidade de horário; e 70,9\% podem escolher ou remanejar seu horário de trabalho sob certas condições negociadas com a organização onde atuam.

A seguir serão apresentados os principais desafios para professores orientadores, supervisores nas organizações e estagiários. 


\section{DESAFIOSPARAPROFESSORESORIENTADORESNAIES, SUPERVISORES NAS ORGANIZAÇÕES E ESTAGIÁRIOS}

As orientações que os estudantes precisam receber dos professores orientadores nas IES são essenciais ao processo de estágio supervisionado, do mesmo modo que aquela recebida dos supervisores no local de estágio, por meio de encontros sistemáticos com estes profissionais.

Neste sentido, uma questão tratava da frequência das orientações recebidas do supervisor no local de estágio: $7,6 \%$ dos estudantes responderam que não receberam nenhuma orientação no local de estágio; 24,I\% disseram receber orientações esporadicamente; $17,7 \%$ receberam de uma a duas vezes no mês; $27,8 \%$ de uma a duas vezes na semana; e $22,8 \%$ relataram receber orientações diariamente (Gráfico 2).

Para Sancovschi, Fernandes e Siqueira (2009), quando as empresas oferecem oportunidades de estágio elas submetem-se a fornecer as primeiras experiências profissionais para os estudantes. Os estudantes avaliaram a qualidade das orientações recebidas nas organizações: $36,7 \%$ consideraram as orientações recebidas nas organizações como apenas suficiente; $17,7 \%$ as avaliaram como excelente; $22,8 \%$ como muito boa; e $22,8 \%$ como ruim ou péssima (Gráfico 3).

Gráfico 2 Orientações no Local de trabalho

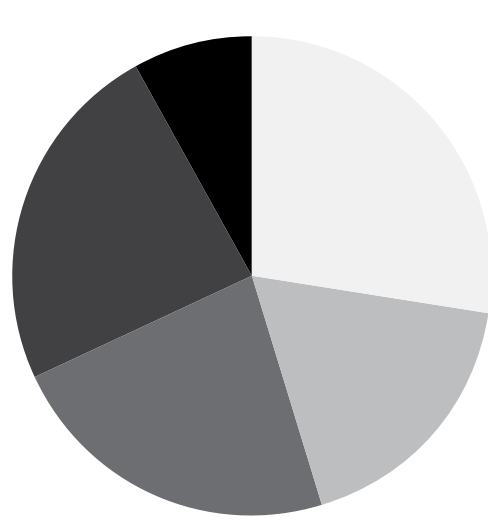

7\% Não recebi orientação

$24 \%$ Esporadicamente

23\% Diariamente

18\% De uma a duas vezes no mês

$28 \%$ De uma a duas vezes na semana 
Gráfico 3 Qualidade percebida das orientações no local de trabalho

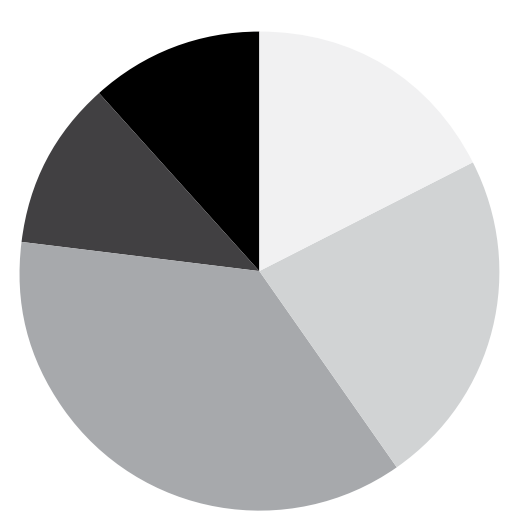
$11 \%$ Péssima
$11 \%$ Ruim
$37 \%$ Suficiente
$23 \%$ Muito Bom
$18 \%$ Excelente

Em relação às orientações recebidas do professor orientador na universidade, durante a disciplina de estágio obrigatório: 40,5\% dos estudantes entrevistados responderam ter realizado cinco ou mais encontros sistemáticos com os professores orientadores; $15,2 \%$ dos estudantes tiveram quatro encontros, número de encontros previstos na disciplina de estágio; $38 \%$ receberam de uma a três orientações (número abaixo dos encontros previstos na disciplina de estágio obrigatório supervisionado); e 6,3\% alegam não terem encontrado com o professor orientador indicado pela IEs (Gráfico 4). Quanto à qualidade dessas orientações: $18,5 \%$ a avaliaram como excelente; $25,9 \%$ a avaliaram como muito boa; $40,7 \%$ como apenas suficiente; $7,4 \%$ como ruim; e 7,4\% como péssima (Gráfico 5). 
Gráfico 4 Orientações na IES
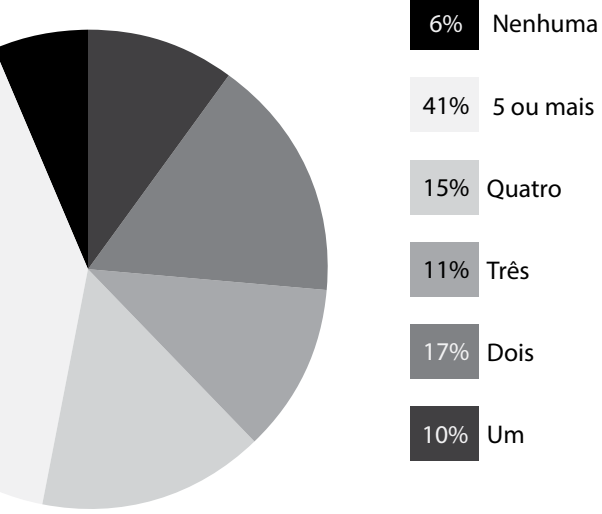

Gráfico 5 Qualidade Percebida das Orientações na IES

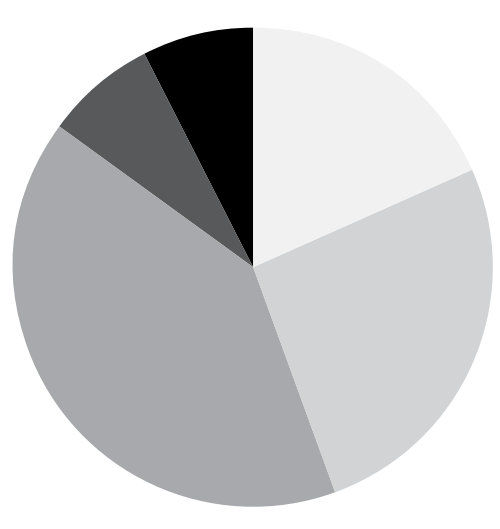

7\% Péssima

7\% Ruim

$41 \%$ Suficiente

$26 \%$ Muito Bom

$19 \%$ Excelente

Para Carvalho (2009), o professor orientador precisaria analisar os problemas encontrados e as atividades realizadas pelos estagiários nas organizações. Para tanto, seria imprescindível realizar encontros sistemáticos com os estagiários. De acordo com Rodrigues e Carmo (2010), o professor orientador seria fundamental na relação entre a unidade de ensino e organizações, pois teria a visão do processo de aprendizagem como um todo; assim, a ausência 
de contato ou o pouco contato com o professor orientador comprometeria o processo de aprendizagem possibilitado pelo estágio.

Para Roesch (2005), "o papel do orientador é prover meios (facilitar contatos, indicar bibliografia, sugerir métodos e técnicas) e incentivar o trabalho do acadêmico; mas, a qualidade final é da maior responsabilidade do acadêmico (ROESCH, 2005)". Contudo, este fato não exclui professores orientadores e supervisores de sua participação fundamental no processo de estágio; permanece assim, o desafio para professores orientadores e supervisores de estabeleceram agendas para encontros sistemáticos e de qualidade com os estagiários nas instituições de ensino, assim como nos locais de estágio.

Deste modo, entre os principais desafios relatados pelos estagiários estão a "falta de orientação pelos professores designados pela IEs como orientadores" e a "falta de supervisão no local de estágio". Apesar destas dificuldades, os estudantes relataram que o estágio: "oportunizou obter conhecimento global da organização"; "possibilitou a realização de diagnóstico, identificação e tratamento de uma situação problema tendo por base os conhecimentos teóricos apreendidos durante o curso"; "contribuiu para o aperfeiçoamento das habilidades para relacionamento interpessoal"; e "estimulou a criatividade, a inovação e habilidades de comunicação".

Quando questionados sobre a permanência do estágio supervisionado obrigatório no Curso de Administração, 64,6\% dos entrevistados optaram pelo estágio supervisionado obrigatório; e 30,4\% preferiam elaborar um Trabalho de Conclusão de Curso, ao invés de realizar o estágio supervisionado. $\mathrm{O}$ Trabalho de Conclusão de Curso não está presente no atual projeto pedagógico do curso, que os estudantes participantes deste estudo frequentam.

Em relação às expectativas que os estudantes tinham quanto ao estágio supervisionado obrigatório: para 24,1\% dos estagiários entrevistados o estágio atingiu plenamente as expectativas que possuíam; para 32,9\% atendeu à maior parte das expectativas; para 27,8\% atendeu parcialmente e para $6,3 \%$ o estágio não atendeu às expectativas que possuíam em relação ao estágio supervisionado obrigatório. Em relação aos desafios e dificuldades na 
IES e nas organizações, foram elaboradas questões abertas, cujos resultados serão apresentados a seguir.

\section{ABORDAGEM QUALITATIVA}

Para a abordagem qualitativa foram elaboradas quatro questões abertas, em que os alunos expressavam de maneira livre as suas opiniões sobre os desafios e dificuldades no processo de estágio supervisionado, na instituição de ensino e na empresa onde realizavam o estágio. Para o tratamento destas questões abertas foi utilizada a técnica da análise temática ou categorial, que, de acordo com Bardin (20II), baseia-se em operações de desmembramento do texto em unidades, ou seja, em descobrir os diferentes núcleos de sentido que constituem a comunicação, e posteriormente, realizar o seu reagrupamento em classes ou categorias.

Seguindo os procedimentos de Bardin (20II), na fase de codificação do material, foram feitos recortes em unidades de contexto e de registro, e a categorização. A unidade de registro (UR), "é a unidade de significação codificada e corresponde ao segmento de conteúdo considerado unidade de base, visando à categorização e à contagem frequencial" (BARDIN, 20II, p. 134). Embora de dimensão variável é o menor recorte de ordem semântica que se liberta do texto, podendo ser uma palavra chave, um tema, objetos, personagens etc. A unidade de contexto (UC) "serve de unidade de compreensão para codificar a unidade de registro e corresponde ao segmento da mensagem, cujas dimensões (superiores às da unidade de registro) são ótimas para que se possa compreender a significação exata da unidade de registro" (BARDIN, 20II, p. I37).

Dentro do discurso dos estagiários da IEs foram observadas as seguintes categorias: I. Dificuldades encontradas pelos estagiários na instituição de ensino; 2. Dificuldades encontradas pelos estagiários nas organizações onde realizaram o estágio; 3. Sugestões de melhorias quanto ao estágio na empresa; 4. Sugestão de melhorias quanto ao estágio na instituição de ensino. Para exemplificação, as categorias de maior destaque pela frequência de depoimentos bem como de número de unidades de contexto (e registro) estão descritas a seguir. 
Para a categoria (I) - Dificuldades encontradas pelos estagiários na instituição de ensino - apareceram em grande frequência as palavras-chave "burocracia"; "demora" (UR); "não encontrar" (UR) e "pouco tempo" (UR), dentro das seguintes unidades de contexto (UC), que trazem a compreensão da unidade de registro: "excesso de burocracia no sentido pejorativo da palavra, onde se encontra dificuldade para conciliar todas as assinaturas necessárias"; "demora no retorno das correções dos trabalhos" (Uc); "não encontrar o professor pessoalmente na Instituição no horário agendado para a orientação" (UC); e "pouco tempo de orientação" (UC).

Assim, as principais dificuldades encontradas pelos estagiários na instituição de ensino são concernentes ao relacionamento professor-aluno, e estudos apontam que o professor assume atitudes que podem facilitar ou dificultar o processo de desenvolvimento do estágio. Neste sentido, MurrayHarvey (200I apud CHU; KWAN; WARNING, 20I2) investigaram as fontes de apoio dadas aos estudantes pelos professores, e os resultados revelaram que os estudantes atribuem alto valor ao apoio emocional dos professores, bem como à sua colaboração e ao feedback. Valsecchi e Nogueira (2002) identificaram aspectos relacionados à comunicação professor-aluno em estágio supervisionado, e o estudo confirmou que a comunicação professoraluno foi o marco divisor para que o aluno tivesse ou não desempenho satisfatório no estágio supervisionado, e que a presença solidária do professor, mediando o processo ensino-aprendizagem e a abertura para o diálogo, é o principal aspecto positivo.

Verifica-se, portanto, a importância de relações efetivas entre professor e estudante como força motriz na condução da aprendizagem, que fica facilitada quando o professor abre espaço para que o aluno exprima seus sentimentos e emoções, e dificultada quando o professor assume atitude de distanciamento na condução da orientação de estágio, não percebendo a realidade do estudante, que já tem de enfrentar o despreparo ao vivenciar o primeiro contato com a prática.

Para a categoria (2) - Dificuldades encontradas pelos estagiários nas organizações onde realizaram o estágio - apareceram em grande frequência as palavras-chave "conciliar" (UR) e "falta" (UR), dentro das seguintes 
unidades de contexto (UC): "dificuldade em conciliar o estágio com os estudos" (UC); e "falta de supervisão na empresa" (UC).

Essas falas mostram que é necessário compreender a complexidade das questões relacionadas com a formação do administrador, visando a permitir que ele concilie estágio e estudo, para que possa relacionar, conforme assevera Drucker (1988), a sua especialidade com o universo de conhecimento e a relacioná-la, na prática, juntamente com outras disciplinas, aos resultados finais. "Não sabemos executar qualquer dessas tarefas atualmente - o que explica por que os estudantes de hoje estão tão profundamente insatisfeitos." (DRUCKER, 1988, P. 390).

Outro aspecto que evidencia a "falta de supervisão na empresa" é questionado por Medeiros (2006): como os cursos de administração podem compatibilizar as estruturas existentes de reprodução de conhecimento com as complexas situações organizacionais reais com as quais o estudante se depara e deve compreender?

Para a categoria (3) - Sugestões de melhorias quanto ao estágio na empresa - as palavras-chave (UR) foram: "orientação" (UR) e "reuniões" (UR), dentro das seguintes unidades de contexto (UC): "passar orientações para o estudante" (UC) e "fazer mais reuniões para acompanhar o programa de cada um" (UC).

O contato estabelecido entre estagiário e supervisor deveria acontecer numa dimensão muito mais ampla, não se limitando à discussão de ideias, mas propiciando a implementação de atividades (FLORES; DIAS; FLORES, 2007), o que beneficiaria não apenas o estudante, mas também os professores e a própria organização concedente.

Ao intermediar os contatos entre a organização e a instituição de ensino, o estagiário pode trazer novas idéias e soluções criativas para problemas práticos. Pode contribuir, também, para que o seu supervisor tenha acesso a conceitos teóricos e procure se reciclar. Para Sendin (2002 apud FLOREs; DIAS; FLORES, 2007), estagiário e supervisor, juntos, podem causar impacto positivo em toda a equipe, aumentando a produtividade. "As competências do administrador estão associadas a uma visão da organização em sua totalidade, e não apenas em atividades e tarefas isoladas." (FARIA, 20I2, p. 2). 
Para a categoria (4) - Sugestão de melhorias quanto ao estágio na instituição de ensino - as unidades de referência e as unidades de contexto foram: "orientação" e "trabalho de conclusão de curso", dentro das seguintes unidades de contexto (Uc): "quantidade de orientandos e horário disponível para orientação no horário de aula do aluno" (UC), e "o estágio supervisionado poderia ser realizado no decorrer de todo ano, nos moldes de um TCC" (UC).

Com relação à qualidade das orientações recebidas no local do estágio, não há um número expressivo que demonstre a satisfação por parte dos estudantes com suas respectivas organizações. Em contrapartida, eles afirmaram ter orientações em número suficiente por parte dos professores orientadores, e poucos as qualificaram como "ruim" ou "péssima", o que pode explicar o desejo de realizarem Trabalho de Conclusão de Curso, Iniciação Científica ou Monitoria, oportunidades estas em que trabalhariam apenas sob a orientação do professor, ao invés de realizarem o estágio supervisionado.

Neste sentido, em estudo de caso no curso de Administração de uma Instituição de Ensino Superior (IES), Nunes, Patrus-Pena e Dante (20II) mostraram a dificuldade de avaliação do processo de formação e de sua eficácia, tendo em vista que as competências podem ser adquiridas pelos estudantes, por meio de variados processos: educação formal, experiência profissional e experiência social, o que pode refletir uma dificuldade do aluno para discernir quais experiências e processos contribuem para o desenvolvimento de cada uma das competências.

O Trabalho de Conclusão de Curso, vinculado ou não a uma atividade de estágio, complementa a formação profissional do aluno, e pode vir a ser uma melhoria no estágio. Este fato surgiu das falas dos alunos como forma de, a exemplo dos estágios, obterem-se experiências vividas que, segundo Santos e Silva (2012), representam a vida como um todo. Não se vive sem experiências e nem há experiências sem vida, o que implica dizer que as experiências são responsáveis pela formação do indivíduo, transformando-o a cada situação - positiva ou negativamente. "Experiência 
não é necessariamente o que se faz, mas refere-se ao que acontece na vida das pessoas e traz algum significado para elas.” (sILVA, 20I2, p. 27).

Os resultados da abordagem qualitativa completaram os dados da abordagem quantitativa, e possibilitaram algumas conclusões ou considerações, descritas a seguir. 


\section{CONSIDERAÇÕES FINAIS}

Este trabalho surgiu das inquietações geradas da necessidade de, na condição de professores e pesquisadores na área de ensino da administração, verificar e analisar o processo de estágio supervisionado do Curso de Administração de uma IEs, na visão dos acadêmicos, que já realizaram o estágio, visando a avaliar tanto os aspectos positivos quanto aqueles que precisam ser melhorados no processo de estágio, na percepção dos estagiários, bem como ter ciência dos aspectos mais centrais neste processo.

Os resultados obtidos podem ser relevantes para o meio acadêmico, pois, mostram que a voz dos estudantes fala sobre os desafios no processo de orientação encontrados pelos professores designados pela IEs como orientadores e para a carência de supervisão no local de estágio. Estes aspectos precisam ser melhorados, pois o estágio supervisionado é fundamental para a formação do acadêmico; assim, professores orientadores e supervisores no local de estágio precisam estar mais engajados neste processo. Os resultados apontam ainda que, com relação às principais dificuldades na IES, os estudantes mencionaram questões relacionadas à burocracia e às orientações. Quanto às dificuldades encontradas na empresa que oferece o estágio, os estudantes mencionaram a dificuldade em conciliar o estágio com os estudos e a falta de supervisão na empresa. As possibilidades encontradas no decorrer do estágio compreendem: obter conhecimento global acerca da organização; realizar diagnóstico, identificação e tratamento de uma situação problema, tendo por base os conhecimentos teóricos apreendidos durante o curso; contribuir para o aperfeiçoamento das habilidades para o relacionamento interpessoal; e estimular a criatividade, a inovação e as habilidades de comunicação.

Por fim, cabe ressaltar outro questionamento que pode feito em relação ao processo de estágio supervisionado: o fato de alguns estudantes preferirem realizar outras atividades ao invés de realizar o estágio (caso esta opção fosse oferecida pela IEs em questão). Tal fato vai ao encontro da nova lei de estágio, a Lei $n^{\circ}$ Ir.788, que no parágrafo $3^{\circ}$ no artigo $2^{\circ}$ estabelece que as atividades de extensão, de monitorias e de iniciação científica na educação 
superior, realizadas pelo estudante, poderão ser equiparadas ao estágio, quando previsto no projeto pedagógico do curso (BRASIL, 2008)

Acredita-se que este trabalho poderá contribuir para que o Curso de Administração da IEs pesquisada, assim como outros cursos de Administração de outras IES possam refletir sobre as possibilidades de aprimoramento do processo de orientação e de supervisão dos estágios.

Como limitação deste estudo, aponta-se que a pesquisa foi realizada somente com estudantes; não foram entrevistados os professores orientadores, assim como os supervisores nas organizações. Deste modo, como sugestão para futuras pesquisas, podem ser realizados estudos que concedam voz aos professores orientadores de estágio supervisionado e às organizações que concedem estágio, na intenção de ampliar as discussões sobre o processo de estágio supervisionado nas Instituições de Ensino Superior, que ofertam cursos na área de Administração, além de possibilitar um entendimento do fenômeno sob diferentes vertentes. 


\section{REFERENNCIAS}

ALBUQUERQUE, L. S.; SILVA, E. M. Pontos positivos e negativos do estágio na formação profissional dos estudantes de ciências contábeis da cidade de Caruaru-Pe. In: ENCONTRO DA ASSOCIAÇÃO NACIONAL DE PÓS-GRADUAÇÃO E PESQUISA EM ADMINISTRAÇÃO, 30., 2006, Salvador. Anais... Salvador: AnPAD, 2006.

ALMEIDA, D. R.; LAGEMANN, L.; SOUZA, S. V. A. A importância do estágio supervisionado para a formação do administrador. In: ENCONTRO DA ASSOCIAÇÃO NACIONAL DE PÓSGRADUAÇÃO E PESQUISA EM ADMINISTRAÇÃO, 30., 2006, Salvador. Anais... Salvador: AnPAD, 2006.

ANGRAD/CFA - ASSOCIAÇÃO NACIONAL DOS CURSOS DE GRADUAÇÃO EM ADMINISTRAÇÃO / CONSELHO FEDERAL DE ADMINISTRAÇÃO. Comunicado Nacional de 20 de setembro de 2005. Diretrizes Curriculares Nacionais para os Cursos de Graduação em Administração. Rio de Janeiro: 2005. Disponível em: <www.angrad.org.br>. Acesso em: 24/09/20I0.

AQUINO, R. D.; TOMASSINI, R. Os estágios curriculares e suas representações sociais segundo os graduandos em administração. In: ENCONTRO DA ASSOCIAÇÃO NACIONAL DE PÓSGRADUAÇÃO E PESQUISA EM ADMINISTRAÇÃO, 32., 2008, Rio de Janeiro. Anais... Rio de Janeiro: AnPAD, 2008.

ARAÚJO, G. D. et al. O desenvolvimento do pensamento reflexivo no curso de Administração. In: ENCONTRO DA ASSOCIAÇÃO NACIONAL DE PÓS-GRADUAÇÃO E PESQUISA EM ADMINISTRAÇÃO, 36., 20I2, Rio de Janeiro. Anais... Rio de Janeiro: AnPAD, 2012.

BARDIN, L. Análise de conteúdo. São Paulo: Edições 70, 201 I.

BRASIL. Lei Federal no 6.494 de 07 de dezembro de 1977. Diário Oficial da República Federativa do Brasil. Poder Executivo, Brasília, DF, 9 de dezembro de 1977.
B R A S I L.
P A R E C E R
C Â M A R A
D E
E N S I N O

SUPERIOR/CONSELHO NACIONAL DE EDUCAÇÃO I46/2002. Ministério da Educação e do Desporto. Brasília, DF, 03 de abril de 2002.

BRASIL. RESOLUÇÃO CÂMARA DE ENSINO SUPERIOR/CONSELHO NACIONAL DE EDUCAÇÃO 04/2005. Ministério da Educação e do Desporto. Brasília, DF, I3 de julho de 2005.

BRASIL. Lei Federal no II.788 de 25 de setembro de 2008. Diário Oficial da República Federativa do Brasil. Poder Executivo, Brasília, DF, 25 de setembro de 2008.

BRASIL. Decreto lei no 87.497. Ministério da Educação e do Desporto. Brasília, DF, I8 de agosto de 1982.

BRASIL. RESOLUÇÃO CÂMARA DE ENSINO SUPERIOR/CONSELHO NACIONAL DE EDUCAÇÃO 04/2005. Ministério da Educação e do Desporto. I3 de julho de 2005.

BURIOLLA, M.A.F. Supervisão em Serviço Social: o supervisor, sua relação e seus papéis. 4. ed. São Paulo: Cortez, 2008. 
CARVALHO, M. I. As dimensões pedagógicas e sociais da prática de estágio. Extra-Classe: Revista de Trabalho e Educação. Belo Horizonte, n. 2, v. 2, jul/dez. p. 80-I04, 2009.

CHU, S. K. W.; KWAN, A. C. M.; WARNING, P. Blogging for information management, learning, and social support during internship. Educational Technology \& Society, v. I5, n. 2, I68-178, 2012.

CNAE - CLASSIFICAÇÃO NACIONAL DE ATIVIDADES ECONÔMICAS. Versão 2.o. (CNAE/IBGE), Rio de Janeiro, IBGE, 2007.

D’ABATE, C. P.; YOUNDT, M. A.; WENZEL, K. E. Making the most of an internship: an empirical study of internship satisfaction. Academy of Management Learning \& Education. v. 8, n. 4, p. 527-539, 2009.

DIAS, S. M. R. C.; PATRUS, R.; MAGALHÃES, Y. T. de. Quem ensina um professor a ser orientador? Proposta de um modelo de orientação de monografias, dissertações e teses. Administração: Ensino e Pesquisa. Rio de Janeiro, v. I2, n. 4, p. 697-72I, 201 I.

DRUCKER, P. F. As fronteiras da Administração: onde as decisões do amanhã estão sendo determinadas hoje. São Paulo: Pioneira, 1988.

FARIA, E., et al. A formação profissional de estudantes de administração: a experiência do estágio supervisionado obrigatório. SIPE (Sistema Integrado de Publicações Eletrônicas da Faculdade Araguaia). Anuário Discente (ISSN 2238-6778), v. I, n. I, 2012.

FESTINALLI, R. C.; CANOPF, L.; BERTUOL, O. Inquietações sobre o Estágio Supervisionado e a Formação do Administrador. In: ENCONTRO DA ASSOCIAÇÃO NACIONAL DE PÓSGRADUAÇÃO E PESQUISA EM ADMINISTRAÇÃO, 3I., 2007, Rio de Janeiro. Anais... Rio de Janeiro: AnPAD, 2007.

FLORES, L. C. da S.; DIAS, M. A. H.; FLORES, R. O. M. S. Estágio curricular do Curso de Administração do Centro de Ciências Sociais Aplicadas - elemento de integração - Empresa Universidade. In: COLOQUIO INTERNACIONAL SOBRE GESTION UNIVERSITARIA EM AMERICA DEL SUR, 7., Anais... Mar del Plata, Argentina. 29 de Nov-or de dez, 2007.

FONSECA, J. S. P., et al. A influência da Formação em administração nas Habilidades e Competências do Administrador (Futuro e Atual). 2007. In: ENCONTRO DA ASSOCIAÇÃO NACIONAL DE PÓS-GRADUAÇÃO E PESQUISA EM ADMINISTRAÇÃO, 3I,. 2007, Rio de Janeiro. Anais... Rio de Janeiro: AnPAD, 2007.

FRANCISCO, A. C.; SANTOS, N. dos. Fatores críticos de sucesso na aquisição de competências no estágio curricular supervisionado: o caso dos cursos de Engenharia do CEFET-PR. Revista Gestão Indústria, v. oI, n. oI, p. 26-36, 2005.

FRANCISCO, T. H., et al. A. O desenvolvimento de competências pela prática do estágio curricular obrigatório do curso de administração da FACIERC. Revista Electrónica de Investigación y Docencia (REID), 3, Enero, 20Io, p. II3-I32. Disponível em: < http://www.revistareid.net/ revista/n3/REIDzart6.pdf $>$. Acesso em: 30/03/2012.

GIL, A. C. Métodos e técnicas de pesquisa social. 5. ed. São Paulo: Atlas, 1999. 
LAVILLE, C.; DIONNE, J. A construção do saber: manual de metodologia da pesquisa em ciências humanas. Porto Alegre: Artes Médicas Sul; Belo Horizonte: Ed. UFMG, 1999.

LIU, Y; XU, J.; WEITZ, B. A. The role of emotional expression and mentoring in internship learning. Academy of Management Learning \& Education, v. Io, n. I, p. 94-IIo, $201 \mathrm{I}$.

MARTINS, G. A.; THEÓPHILO, C. R. Metodologia da investigação científica para ciências sociais aplicadas. 2. ed. São Paulo: Atlas, 2009.

MEDEIROS, C. R. de O. A Contribuição do Estágio Supervisionado para a Formação de Competências do Administrador. In: SEMINÁRIOS EM ADMINISTRAÇÃO FEA-USP, 9., 2006, São Paulo. Anais...São Paulo: [s.n.t.]

MESQUITA, S. M.; FRANÇA, S. L. B. A importância do estágio supervisionado na inserção de alunos de graduação no mercado de trabalho. In: CONGRESSO NACIONAL DE EXCELÊNCIA EM GESTÃO, 7., 20II, Rio de Janeiro. Anais...Rio de Janeiro[s.n.], 20II.

MINTZBERG, H.; GOSLING, J. Educando Administradores além das fronteiras. RAE-Revista de Administração de Empresas. FGV, Rio de Janeiro, v. 43, n. 2, abr/jun. p. 29-43, 2003.

MURARI,J. M. L.; HELAL, D. H. O Estágio e o Desenvolvimento de Competências Profissionais em Estudantes de Administração. In: ENCONTRO DA ASSOCIAÇÃO NACIONAL DE PÓSGRADUAÇÃO E PESQUISA EM ADMINISTRAÇÃO, 34., 20Io, Rio de Janeiro. Anais... Rio de Janeiro: AnPAD, 2010.

MURITIBA, P. M., et al. Relação entre Satisfação com o Curso de Graduação e Estágio Profissional. In: ENCONTRO DA ASSOCIAÇÃO NACIONAL DE PÓS-GRADUAÇÃO E PESQUISA EM ADMINISTRAÇÃO, 32., 2008, Rio de Janeiro. Anais... Rio de Janeiro: AnPAD, 2008 .

NASCIMENTO, L. C.; TEODÓSIO, A. S. S. O Estágio diante dos Desafios do Ensino em Administração: Um Estudo de Caso sobre as Percepções de Alunos e Supervisores. In: ENCONTRO DA ASSOCIAÇÃO NACIONAL DE PÓS-GRADUAÇÃO E PESQUISA EM ADMINISTRAÇÃO, 29., 2005, Brasília. Anais... Brasília: AnPAD, 2005.

NEVES, J. L. Pesquisa qualitativa - características, usos e possibilidades. Caderno de Pesquisas em Administração. São Paulo, USP, v. I, n. 3, 2º sem. 1996. Disponível em: <http://www.ead.fea. usp.br/cadpesq/ arquivos/Co3-arto6.pdf. Acesso em: 07/05/2012.

NUNES, S. C.; PATRUS-PENA, R.; DANTAS, D. C. Do projeto pedagógico ao desenvolvimento de competências no curso de Administração: o processo de ensino-aprendizagem sob o olhar do aluno. In: ENCONTRO DA ASSOCIAÇÃO NACIONAL DE PÓS-GRADUAÇÃO E PESQUISA EM ADMINISTRAÇÃO, 35, 20II, Rio de Janeiro. Anais... Rio de Janeiro: AnPAD, 201.

OLIVEIRA, S. R.; PICCININI, V. C.; RETOUR, D. A Construção do Mercado de Estágios em Administração na cidade de Porto Alegre. In: ENCONTRO DA ASSOCIAÇÃO NACIONAL DE PÓS-GRADUAÇÃO E PESQUISA EM ADMINISTRAÇÃO, 34., 20Io. Rio de Janeiro. Anais.... Rio de Janeiro, 2010.

PICONEZ, S. B. (coord.) A prática de ensino e o estágio supervisionado. 8. ed. Campinas: Papirus, I99I. 
PIMENTA, S. G. O estágio na formação de professores: unidade teoria e prática? São Paulo: Cortez, 1995 .

RICHARDSON, R. J. Pesquisa social: métodos e técnicas. 3 ed. São Paulo: Atlas, 1999.

RODRIGUES, J. S.; CARMO, P. C. C. S. Estágio Supervisionado em Serviço Social: desafios e limites para o supervisor e o discente no processo de formação profissional. Revista UNIABEU. Belford Roxo, v.3, n.5, set./dez., 2010.

ROESCH, S. M. A. Projetos de estágio e de pesquisa em administração: guia para estágios, trabalhos de conclusão, dissertações e estudos de caso. 3 ed. São Paulo: Atlas, 2005.

SANCOVSCHI, M.; FERNANDES, L. J. D.; SIQUEIRA, J. R. M. Custos Pessoais do Empenho Imoderado de Alunos de Cursos de Graduação em Administração nos Estágios: A Relação Entre Empenho dos Alunos, Sobrecarga de Trabalho, Estresse no Trabalho, e Aspectos Significativos da Vida Acadêmica. In: ENCONTRO DA ASSOCIAÇÃO NACIONAL DE PÓS-GRADUAÇÃO E PESQUISA EM ADMINISTRAÇÃO, 33., 2009, São Paulo. Anais... São Paulo: AnPAD, 2009. SANTOS, G. T. dos; SILVA, A. B. da. O papel da experiência na aprendizagem de alunos do curso de Administração. In: ENCONTRO DA ASSOCIAÇÃO NACIONAL DE PÓSGRADUAÇÃO E PESQUISA EM ADMINISTRAÇÃO, 36,. 20I2, Rio de Janeiro. Anais... Rio de Janeiro: AnPAD, 2012.

SCORSOLINI-COMIN, F.; MATIAS, A. B.; INOCENTE, D. F. A formação profissional de estudantes de Administração: Uma experiência de estágio social com jovens abrigados. Revista Brasileira de Orientação Profissional, v. 9, n.I, p. I03-II4, 2008.

SILVA, A. B. da, et al. Dimensões de um sistema de aprendizagem em ação para o ensino de administração. Administração: ensino e pesquisa. Rio de Janeiro, v. I3, n. I, p. 9-4I, jan/fev/mar 2012.

SILVA, E. L. de; MENEZES, E. M. Metodologia da pesquisa e elaboração de dissertação. 3 ed. Florianópolis: Laboratório de Ensino a Distância da UFSC, $200 I$.

TORRES, A. S.; DALFOVO, O. Propor um ambiente para o gerenciamento de projetos na orientação de estágio do curso de administração do IBES-SOCIESC. Revista Interdisciplinar Aplicada. Blumenau, v. 5, n. 3, p. oI-27, Tri. III, $201 \mathrm{r}$.

TRIVIÑOS, A. N. S. Introdução à pesquisa em ciências sociais: a pesquisa qualitativa em educação: o positivismo, a fenomenologia, o marxismo. São Paulo: Atlas, 1987.

VALSECCHI, E. A. de S. da S.; NOGUEIRA, M. S. Comunicação professor-aluno: aspectos relacionados ao estágio supervisionado. Revista Ciência, Cuidado e Saúde. Maringá, v. I, n. I, p. I37-I43, I. sem. 2002.

ZABALZA, M. A. O ensino universitário: seu cenário e seus protagonistas. Porto Alegre: Artmed, 2004. 


\section{DADOS DOS AUTORES}

MARIANE LEMOS LOURENÇO^ ${ }^{\star}$ simari@uol.com.br

Doutora em Psicologia pela USP

Instituição de vinculação: Universidade Federal do Paraná

Curitiba/PR - Brasil

Áreas de interesse em pesquisa: Comportamento Organizacional, Ensino e Pesquisa em Administração, Psicologia e Sustentabilidade.

${ }^{\star}$ Rua Prefeito Lothário Meissner, 632, $2^{\circ}$ andar (DAGA)

Jardim Botánico Curitiba/PR 80210-170

IOMARA SCANDELARI LEMOS iomara.lemos@ufpr.br

Doutora em Administração pela PUC/PR

Instituição de vinculação: Universidade Federal do Paraná

Curitiba/PR - Brasil

Áreas de interesse em pesquisa: Sustentabilidade, Estratégia, Planejamento, Ensino e Pesquisa em Administração e Empreendedorismo.

JOSÉ EDUARDO PÉCORA JUNIOR pecora@ufpr.br

Doutor em Operações e Análise de Decisão pela Université Laval

Instituição de vinculação: Universidade Federal do Paraná

Curitiba/PR - Brasil

Áreas de interesse em pesquisa: Logística, Ensino e Pesquisa em Administração,

Modelagem Matemática e Pesquisa Operacional. 